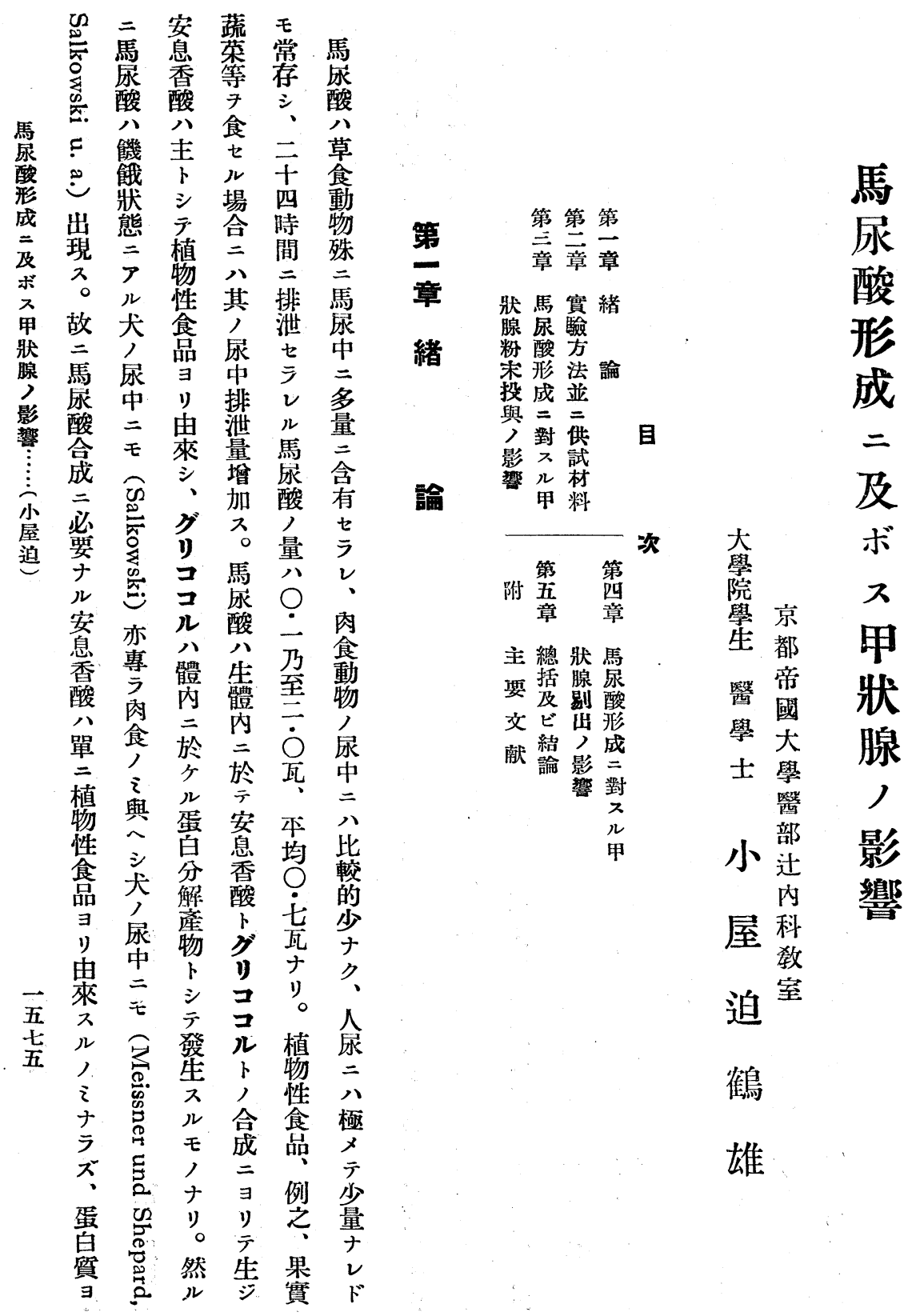




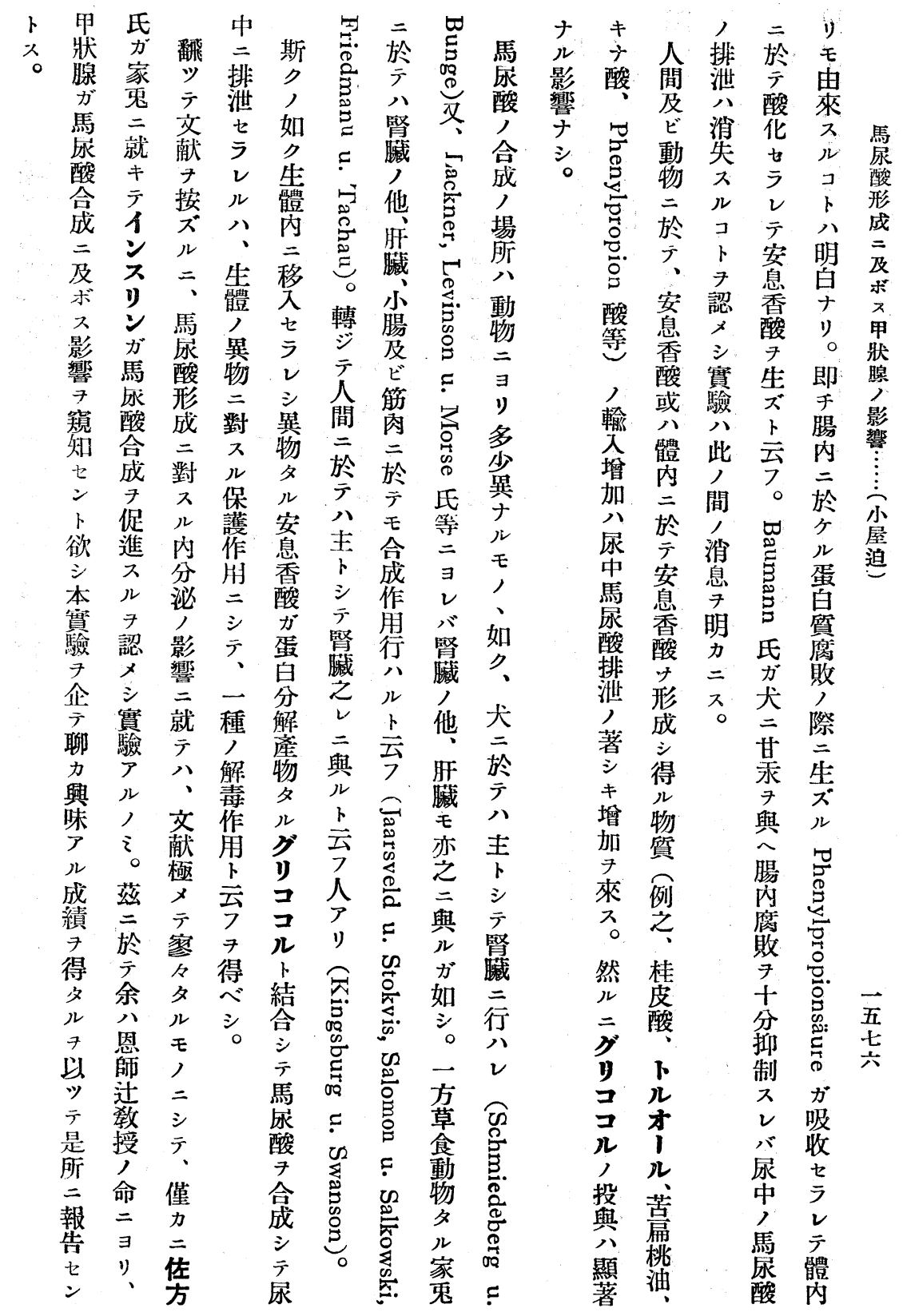




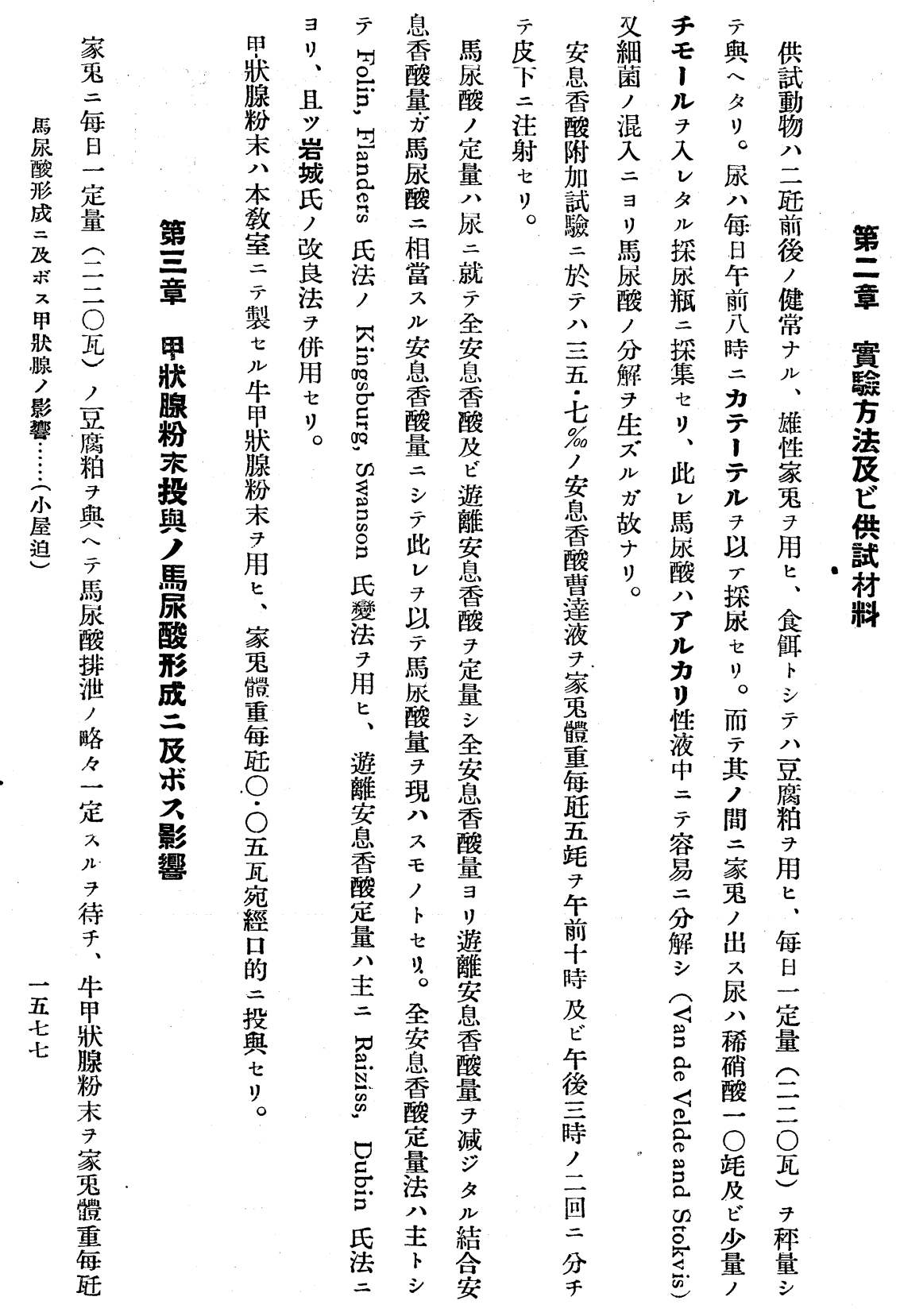


第二表（第十號家鬼 體重 2,000 聒）第一表（第九號家鬼 體重 2,010 㿞）

\begin{tabular}{|c|c|c|c|}
\hline 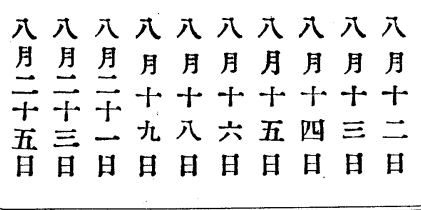 & 時 & 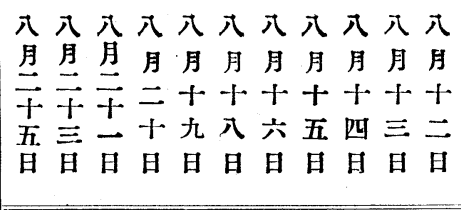 & 日 \\
\hline 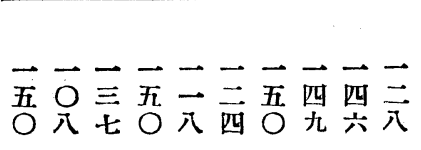 & $\begin{array}{l}\text { 尿 } \\
\text { 最 } \\
\text { 竨 }\end{array}$ & 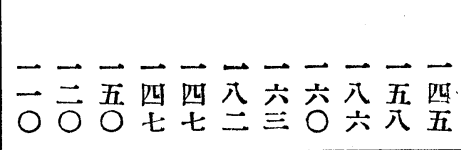 & $\begin{array}{l}\text { 尿 } \\
\text { 量 } \\
\text { 䡛 }\end{array}$ \\
\hline 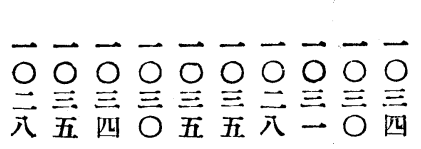 & 重 & 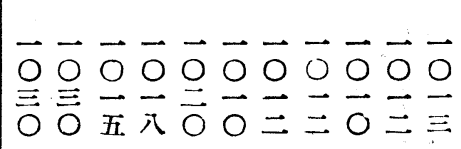 & 比 \\
\hline 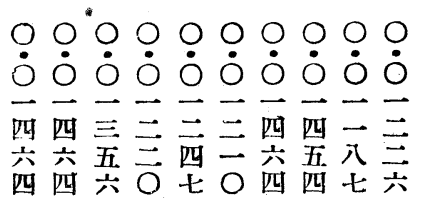 & $\begin{array}{l}\text { 遊 } \\
\text { 離 } \\
\text { 安 } \\
\text { 息 } \\
\text { 香 } \\
\text { 酸 }\end{array}$ & 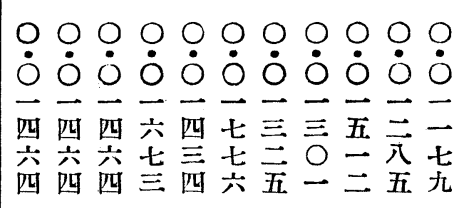 & $\begin{array}{l}\text { 遊 } \\
\text { 離 } \\
\text { 安 } \\
\text { 息 } \\
\text { 香 } \\
\text { 酸 }\end{array}$ \\
\hline 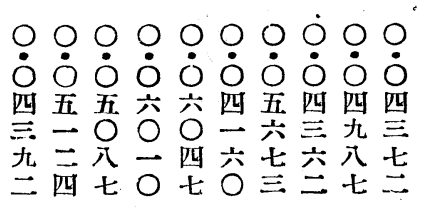 & $\begin{array}{l}\text { 全 } \\
\text { 安 } \\
\text { 息 } \\
\text { 香 } \\
\text { 酸 }\end{array}$ & 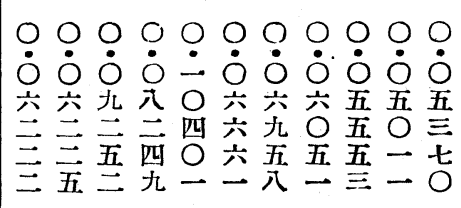 & $\begin{array}{l}\text { 全 } \\
\text { 安 } \\
\text { 息 } \\
\text { 香 } \\
\text { 酸 }\end{array}$ \\
\hline 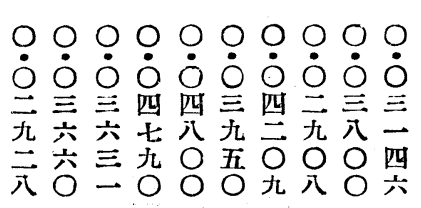 & $\begin{array}{l}\text { 結 } \\
\text { 命 } \\
\text { 安 } \\
\text { 息 } \\
\text { 香 } \\
\text { 酸 }\end{array}$ & 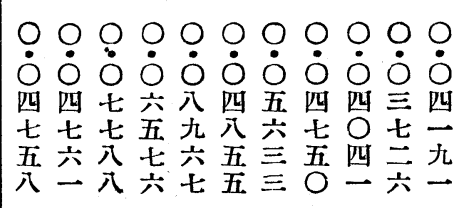 & $\begin{array}{l}\text { 結 } \\
\text { 合 } \\
\text { 安 } \\
\text { 息 } \\
\text { 香 } \\
\text { 酸 }\end{array}$ \\
\hline $\begin{array}{l}\text { 投 } \\
\text { 與 } \\
\text { 中 } \\
\text { 止 }\end{array}$ & $\begin{array}{l}\text { 備 } \\
\text { 考 }\end{array}$ & $\begin{array}{l}\text { 投 } \\
\text { 與 } \\
\text { 中 } \\
\text { 止 }\end{array}$ & $\begin{array}{l}\text { 借 } \\
\text { 考 }\end{array}$ \\
\hline
\end{tabular}

$\left(\begin{array}{l}\text { 容積ハ竨, 重量ハ瓦キ單 } \\ \text { 位トス。以下隼ズ。 }\end{array}\right)$ 
第四表（第十二號家鬼 體重 2.025 䏕）

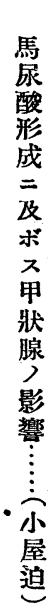

五

\begin{tabular}{|c|c|}
\hline 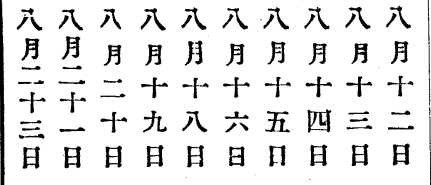 & 時 \\
\hline 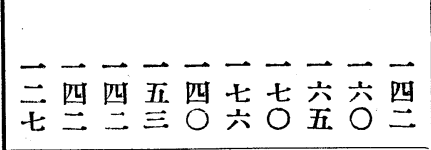 & $\begin{array}{l}\text { 尿 } \\
\text { 量 } \\
\text { 竓 }\end{array}$ \\
\hline 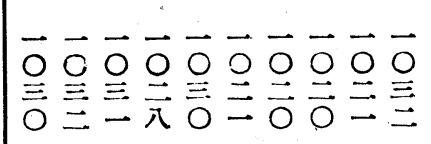 & 比 \\
\hline 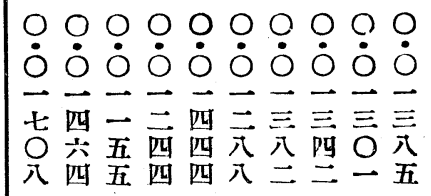 & $\begin{array}{l}\text { 遊 } \\
\text { 離 } \\
\text { 安 } \\
\text { 息 } \\
\text { 香 } \\
\text { 酸 }\end{array}$ \\
\hline 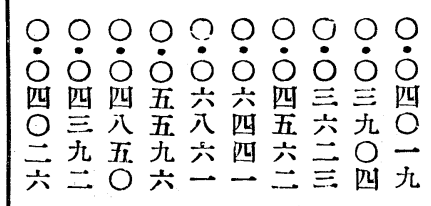 & $\begin{array}{l}\text { 全 } \\
\text { 安 } \\
\text { 息 } \\
\text { 香 } \\
\text { 酸 }\end{array}$ \\
\hline 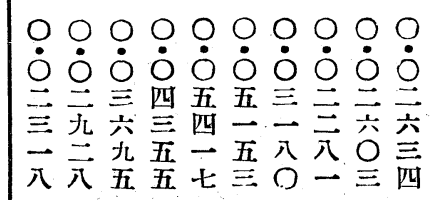 & $\begin{array}{l}\text { 結 } \\
\text { 弇 } \\
\text { 晏 } \\
\text { 息 } \\
\text { 酸 }\end{array}$ \\
\hline $\begin{array}{ll}\text { 投 } & \text { 投 } \\
\text { 與 } & \text { 與 } \\
\text { 中 } & \text { 始 } \\
\text { 止 } & \text { 始 }\end{array}$ & 備 \\
\hline
\end{tabular}

第三表（第十一號家鬼 體重 1.900 咶）

八入八入八入八刀入八刀 月月旦月月月月月月 立示示示十+十+十+1 五三二十九六六五四三二 日昌日日日昌日昌日

$\rightarrow \rightarrow-\rightarrow \rightarrow-\rightarrow-\rightarrow$

只三空三三五五空七四

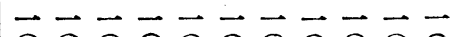

00000000000

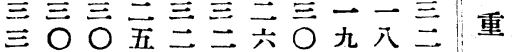

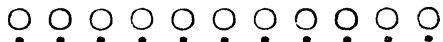
O $\dot{0} \dot{0} \dot{0} \dot{0} \dot{0} \dot{0} \dot{0} \dot{0} \dot{0} \dot{0}$ $\rightarrow \rightarrow \rightarrow-\rightarrow-\rightarrow-\cdots$ 无 $三 \equiv 0$ 三三元三三一

八五二一兆儿盯五七 六六 0 七八四三一九一兀

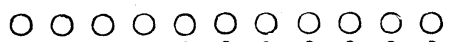
$\dot{0} \dot{0} \dot{0} \dot{0} \dot{0} \dot{0} \dot{0} \dot{0} \dot{0} \dot{0} \dot{0}$ 四四五四五五五四四四四 志四五四五门四公兰七四 二八六三旮的地无

$\dot{0} \dot{0} \dot{0} \dot{0} \dot{0} \dot{0} \dot{0} \dot{0} \dot{0} \dot{0} \dot{0}$

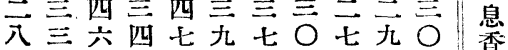

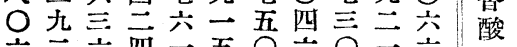
六三六四一五 0 兵 0 二六

\begin{tabular}{|ll|l}
\hline 投 & 投 & 備 \\
與 & 與 & \\
中 & 眥 & 始
\end{tabular}




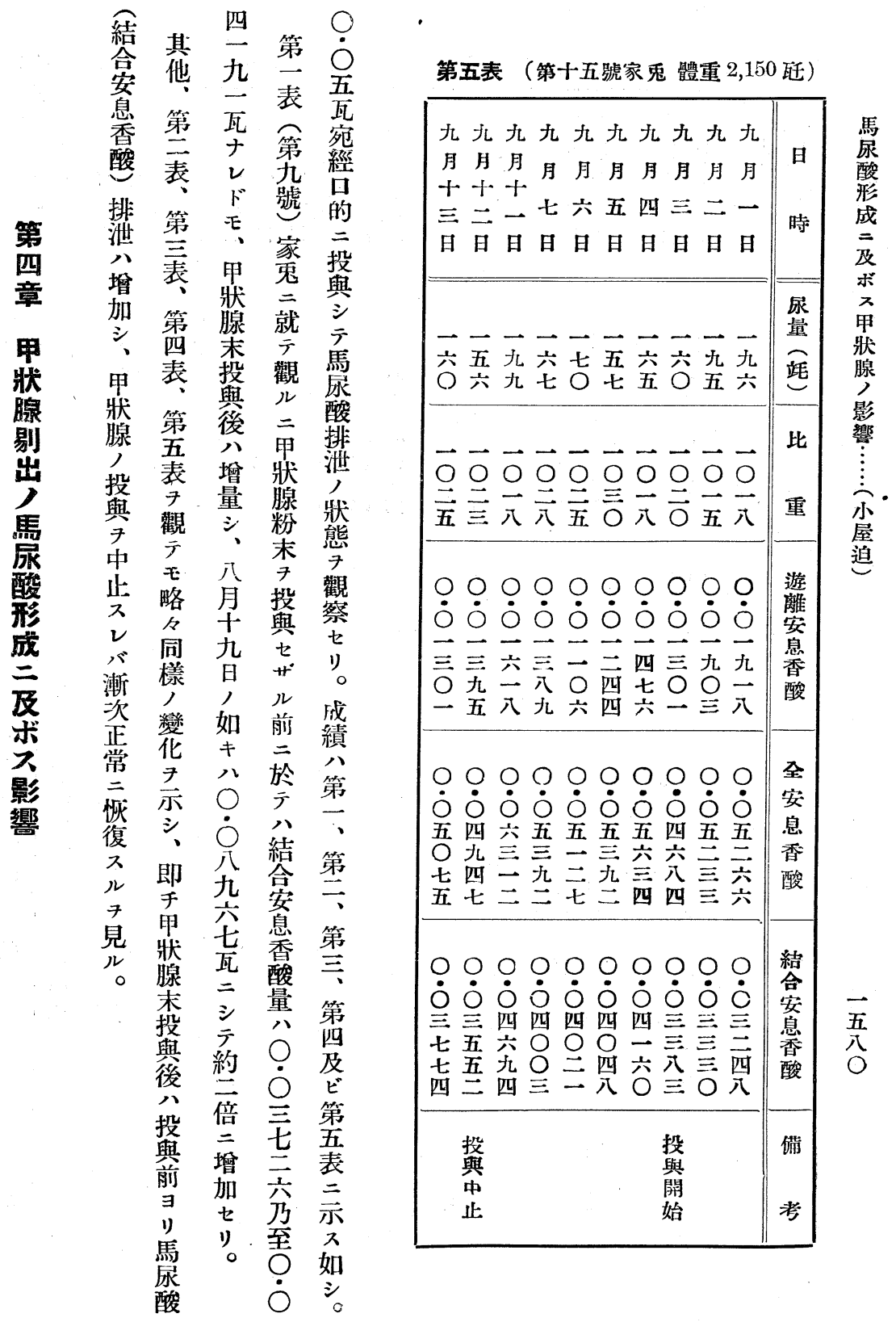




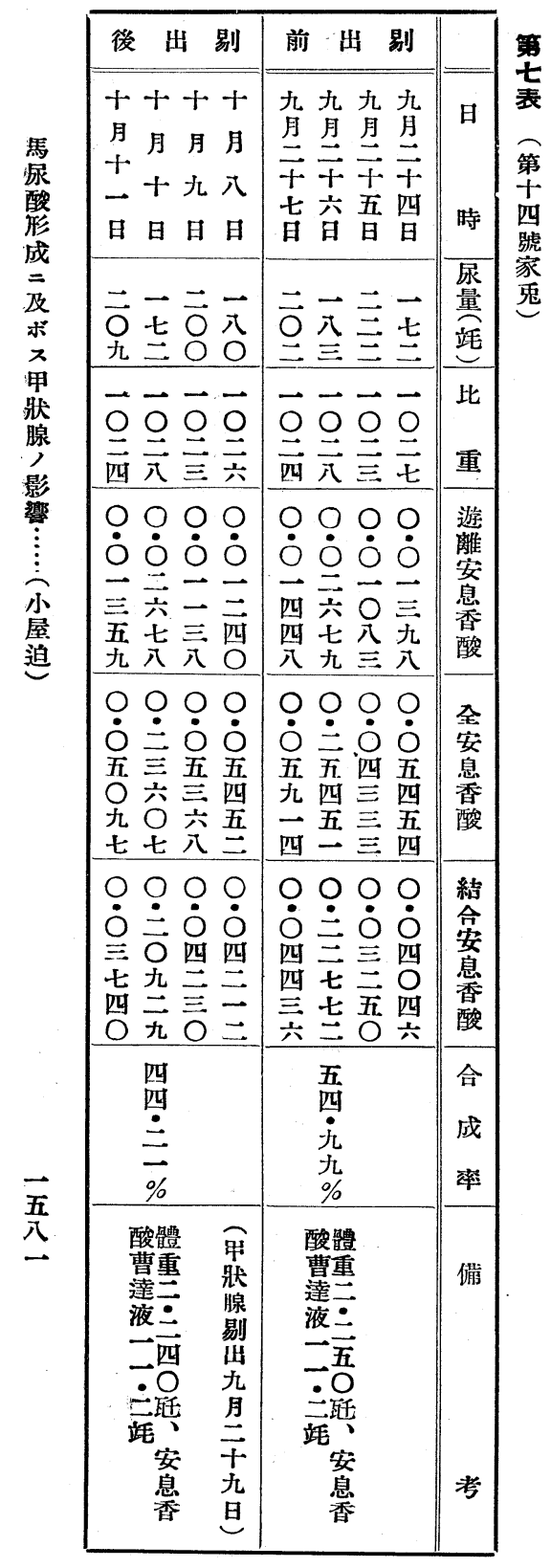

\begin{tabular}{|c|c|c|}
\hline 後 出 剔 & 前 出 剔 & \\
\hline $\begin{array}{l}++十+~ \\
\text { 月 } \text { 月月 } \\
+ \text { 十九 } \\
\text { 日 日 } \\
\text { 日 日 }\end{array}$ & 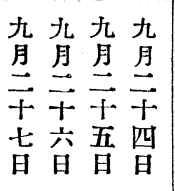 & 日 \\
\hline $\begin{array}{l}\text { 无 } \text { 五 } \\
\text { 九 九 } \\
\text { 九 }\end{array}$ & 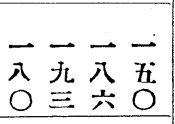 & $\begin{array}{l}\text { 尿 } \\
\text { 量 } \\
\text { 竓 }\end{array}$ \\
\hline 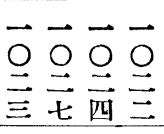 & 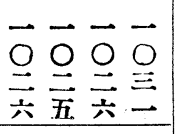 & 比 \\
\hline 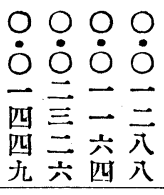 & 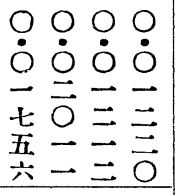 & $\begin{array}{l}\text { 遊 } \\
\text { 離 } \\
\text { 安 } \\
\text { 息 } \\
\text { 香 } \\
\text { 酸 }\end{array}$ \\
\hline 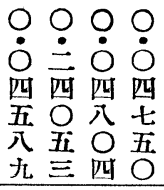 & 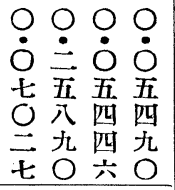 & $\begin{array}{l}\text { 全 } \\
\text { 晏 } \\
\text { 息 } \\
\text { 酸 }\end{array}$ \\
\hline 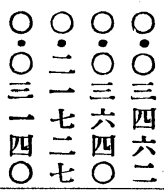 & 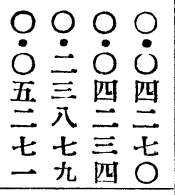 & $\begin{array}{l}\text { 結 } \\
\text { 拿 } \\
\text { 晏 } \\
\text { 息 } \\
\text { 香 } \\
\text { 酸 }\end{array}$ \\
\hline $\begin{array}{l}\text { 五 } \\
\qquad \\
\dot{0} \\
\text { 五 } \\
\%\end{array}$ & $\begin{array}{l}\text { 六 } \\
\text { 方 } \\
\text { 草 } \\
\%\end{array}$ & $\begin{array}{l}\text { 合 } \\
\text { 成 } \\
\text { 率 }\end{array}$ \\
\hline 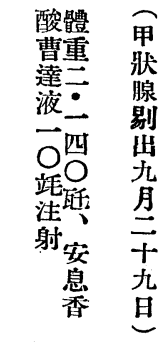 & 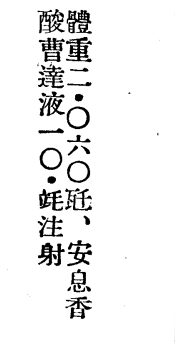 & 備 \\
\hline
\end{tabular}




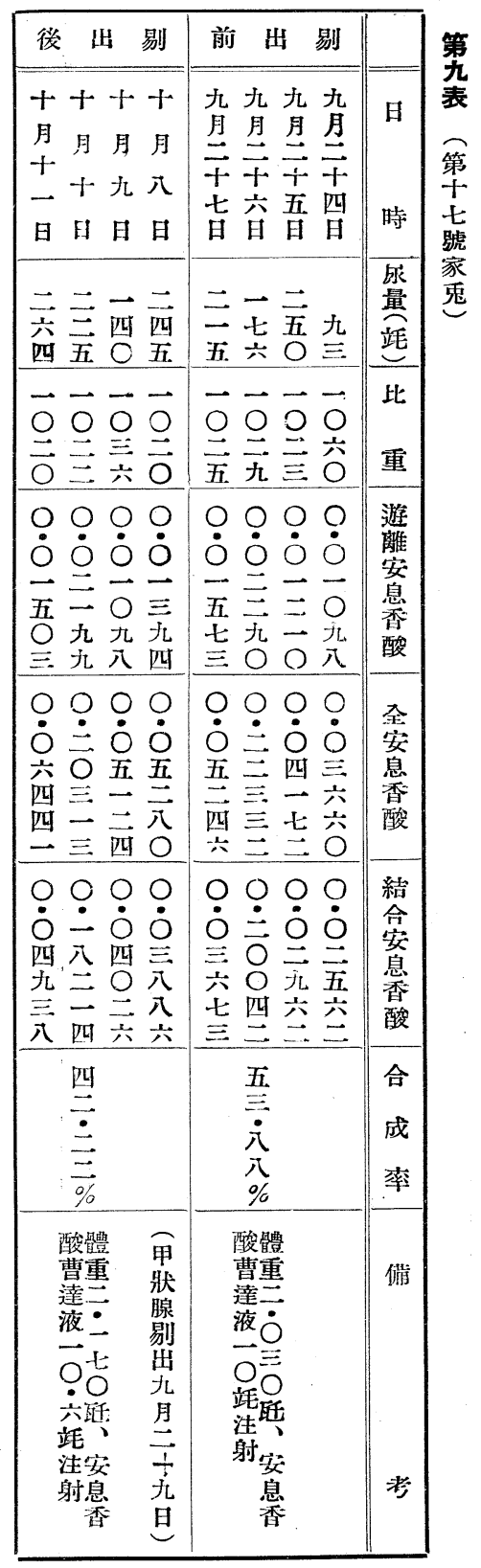

\begin{tabular}{|c|c|c|c|}
\hline 後 出 剔 & 前 仙 剔 & & \multirow{3}{*}{$=\begin{array}{l}\text { 第 } \\
\text { 袁 } \\
\text { 表 } \\
\text { 第 } \\
+ \\
\text { 六 } \\
\text { 號 } \\
\text { 家 } \\
\text { 鬼 }\end{array}$} \\
\hline 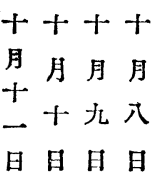 & 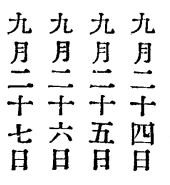 & 日 & \\
\hline 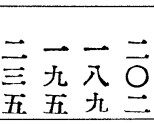 & $\begin{array}{l}\text { 元元 } \text { 六 } \\
\text { 五五 } \\
\end{array}$ & $\begin{array}{l}\text { 尿 } \\
\text { 量 } \\
\text { 竨 }\end{array}$ & \\
\hline 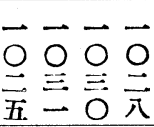 & 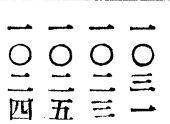 & 比 & \\
\hline 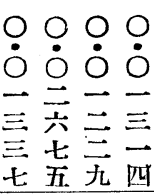 & 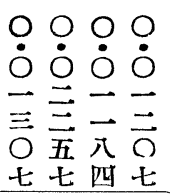 & $\begin{array}{l}\text { 遊 } \\
\text { 離 } \\
\text { 安 } \\
\text { 息 } \\
\text { 香 } \\
\text { 酸 }\end{array}$ & \\
\hline 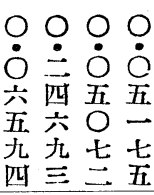 & 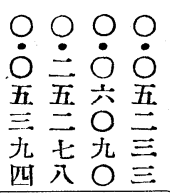 & $\begin{array}{l}\text { 全 } \\
\text { 晏 } \\
\text { 息 } \\
\text { 香 } \\
\text { 酸 }\end{array}$ & \\
\hline 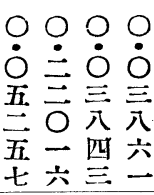 & 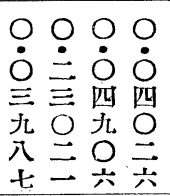 & $\begin{array}{l}\text { 結 } \\
\text { 畣 } \\
\text { 晏 } \\
\text { 息 } \\
\text { 香 } \\
\text { 酸 }\end{array}$ & \\
\hline $\begin{array}{l}\text { 五 } \\
\text { 范 } \\
\vec{\Rightarrow} \\
\%\end{array}$ & $\begin{array}{l}\text { 吾 } \\
\text { 四 } \\
\text { 杂 } \\
\text { 四 } \\
\%\end{array}$ & $\begin{array}{l}\text { 合 } \\
\text { 成 } \\
\text { 來 }\end{array}$ & \\
\hline 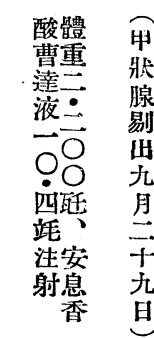 & 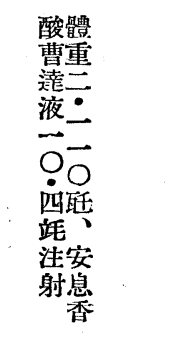 & 考 & \\
\hline
\end{tabular}




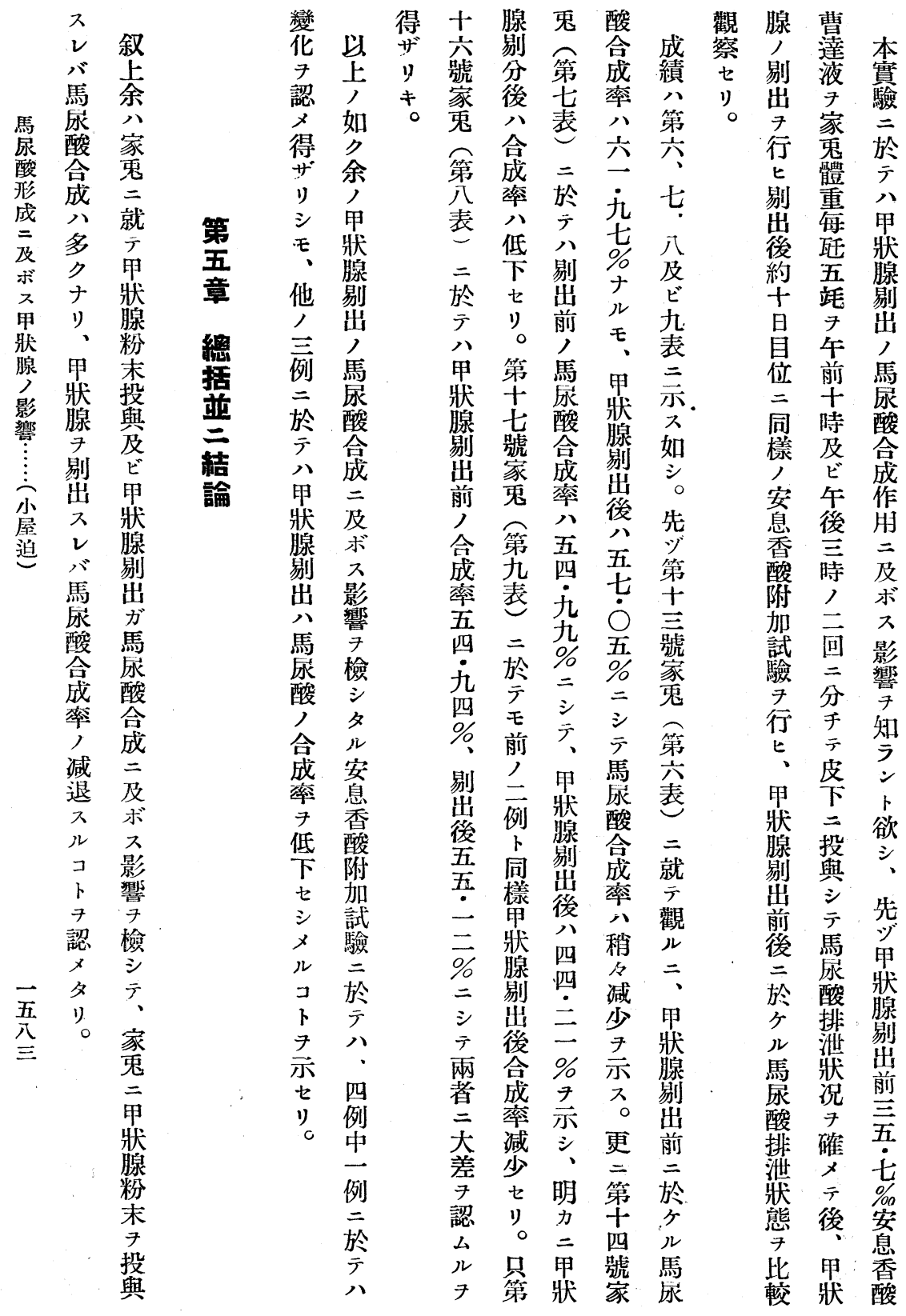




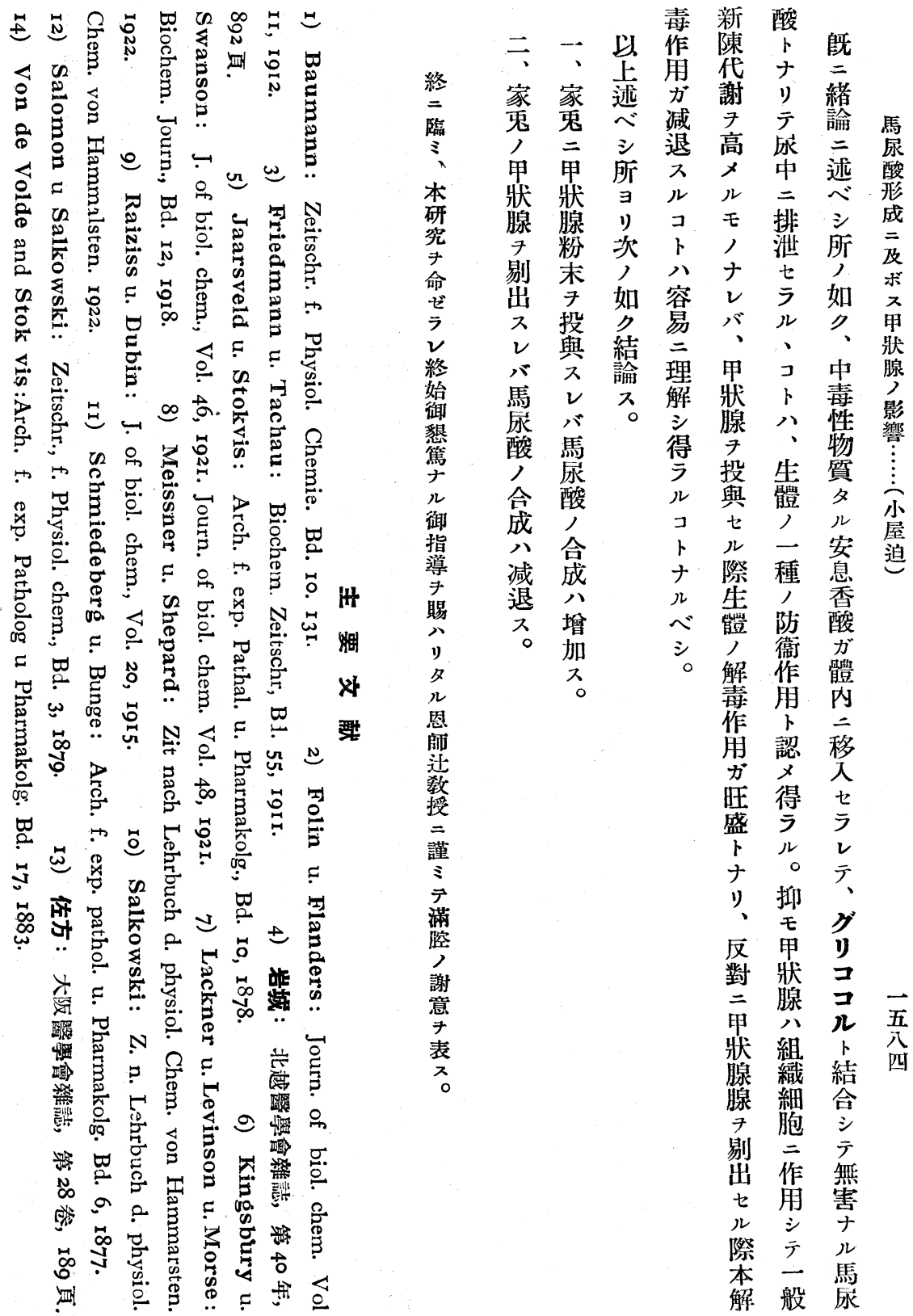


b) Die Gesamt-N-und die Gesamt-S-ausscheidung im Harn waren vermindert und die letztere etwas stärker als die erstere, wodurch der Quotient N/S Zunahme zeigte.

c) Die Aetherschwefelsäure war relativ am deutlichsten vermindert, nächst stark der neutrale Schwefel und am wenigsten die anorganische Schwef elsäure.

2. Einfluss des Ovarialparenchyms.

a) Das Körpergewicht neigte bei den dauernd mit Ovarialparenchym gefütterten Tieren zur Verminderung, während die Harnmenge keine Veränderung aufwies.

b) Die Gesamt-N-und die Gesamt-S-ausscheidung im Harn hatten leichtgradig zugenommen, und zwar die letztere etwas stärker als die erstere.

c) Nach der Unterbrechung der Fütterung mit Ovarialparenchym nahm die Gesamt-S-ausscheidung schneller als die Gesamt-N-ausscheidung ab.

d) Der neutrale Schwefel war relativ am stärksten vermehrt, nächst stark die Aetherschwefelsäure und am wenigsten die anorganische Schwef elsäure.

(Autoreferat)

\title{
Ueber den Einfluss der Schilddrüse auf die Hippursäuresynthese.
}

\author{
Von \\ Dr. T. Koyasako.
}

(Aus der I. med. Klinik der Kaiserl. Universitaet zu Kyoto, Japan Direktor: Prof. Dr. K. Tsuji)

Um den Einfluss der Schilddrüse auf die Hippursäuresynthese festzustellen, hat der Verfasser Versuche an Kaninchen angestellt.

Die Hippursäurebestimmung wurde nach Folin-Flanders, Kingsbury-Swanson u. Raiziss-Dubin ausgeführt.

Die Resultate waren die folgenden:-

I) Bei der Darreichung' von Schilddrüsenpulver nimmt die 
Ausscheidung der Hippursäure im Harn zu.

2) Bei der Exstirpation der Schilddrüse nimmt die Ausscheidung der Hippursäure im Harn ab. (Autoreferat)

\title{
Ueber den Einfluss von Insulin und Adrenalin auf die Hippursäueresynthese.
}

\author{
Von
}

Dr. T. Koyasako.

(Aus der I. med. Klinik der Kaiserl. Universitaet zu Kyoto, Japan.

Direktor: Prof. Dr. K. Tsuji.)

Um den Einfluss von Insulin und Adrenalin auf die Hippursäuresynthese festzustellen, hat der Verfasser Versuche an Kaninchen angestellt.

Die Hippursäurebestimmung wurde nach Folin-Flanders, Kingsbury-Swanson u. Raiziss-Dubin ausgeführt.

Die Resultate waren die folgenden:-

I) Die Einspritzung von Insulin entfaltet keine Wirkung auf die Ausscheidung der Hippursäure.

2) Sowohl die Injektion von Glukose allein als auch die gleichzeitige Injektion von Insulin und Glukose steigert die Ausscheidung der Hippursäure, und zwar ist die Ausscheidung der Hippursäure bei der Injektion von Insulin und Glukose stärker als bei der Injektion von Glukose allein.

3) Bei der Benzoesäureinjektion wirkt das Insulin auf die Hippursäuresynthese fördernd.

4) Bei der Benzoesäureinjektion wirkt das Adrenalin auf die Hippursäuresynthese hemmend.

(Autoreferat)

Druckfehlerberichtigung :

Band VI, Heft X. (I93I), Seite 78, Zeile I6 von oben muss es statt "Vagusendigung" "Sympathicusendigung" und Zeile I7 statt „Sympathicusendigung ",Vagusendigung" heissen. 